\title{
Emergency contraception: lessons learned from the UK
}

\author{
Katie D Schenk, MSc, DLSHTM, Reproductive Health Alliance, London, UK \\ Correspondence/Current Affiliation: Ms K D Schenk, Horizons/Population Council, 4301 Connecticut Avenue NW, Suite \\ 280, Washington DC 20008, USA. Tel: +1 202237 9431. Fax: +1 202237 8410. E-mail: kschenk@pcdc.org
}

(Accepted 7th February 2003)

Journal of Family Planning and Reproductive Health Care 2003; 29(2): 35-40

\begin{abstract}
Context. Since January 2001, women aged over 16 years in the UK have been able to purchase progestogen-only emergency hormonal contraception from pharmacists without prescription. This paper outlines the context in which these changes took place, including contraceptive choices in the UK, changes within the pharmacy profession and political pressures.

Observations. We chart the multisectoral developments required to make emergency contraception (EC) available without prescription in the $U K$, from clinical research findings and results on the views and behaviour of health care professionals and users of EC, through to professional and policy developments, including challenges during and after this process.

Discussion. Lessons learnt from the innovative experience of the deregulation of EC in the UK apply to other regions currently considering similar change. We extrapolate internationally applicable lessons including the importance of stakeholder partnership, transparency and cautious pace of change, and the vital role of professional groups.

Conclusion. Although this change brought a new element of reproductive choice to some women, significant barriers to access to EC still remain for young women and women unable to afford the high price (£24/€37/\$39) of pharmacy purchase in the $U K$.
\end{abstract}

\section{Key message points}

- Communication and co-ordination between all stakeholders are essential to the deregulation of emergency contraception (EC).

- Transparency is vital to respond to challenges and clarify messages to the public.

- Professional groups play a key role in training and information dissemination.

- Access to EC in the UK improved following the legislative change but many women still face barriers to access.

\section{Context}

The UK was the second European country (after France) to make emergency contraception (EC) available from pharmacists without prescription. In the US, EC has recently become available from pharmacists without prescription in Washington State, California and Alaska, and efforts to lobby for wider access in other states continue. This paper examines the context and processes of this change, and lessons learned from this process for groups wishing to promote deregulation elsewhere. (NB. This article is limited to an examination of the provision of hormonal methods for EC, as this was the subject of the legislative change.)

Evidence shows that use of the male condom is high in the UK: $48 \%$ of women in the age range $16-49$ years said that they had used condoms in the previous year, while $21 \%$ identified male condoms as their regular contraceptive method. ${ }^{1}$ Furthermore, $70 \%$ of unwanted pregnancies are predictable (due to unplanned intercourse or condom failure), and about half of unwanted pregnancies result from contraceptive failure rather than lack of use. ${ }^{2-4}$ Since the estimated failure rate for typical use of male condoms is $14 \%$, there is a clear need for EC, in particular among younger and less educated users for whom condom use rates and failure rates are higher. $1,2,5$

The UK has the highest level of teenage pregnancy in Europe: at 24 per 1000 women aged 15-19 years, it is three times as high as France, and six times higher than The Netherlands. While teenage pregnancy rates throughout most of Western Europe have been dropping dramatically since the early 1980 s, rates in the UK have remained at, or above, this level. 6

Pressure to widen the powers of pharmacists has recently increased. Recent reports from the Department of Health suggest innovative ways in which pharmacists' skills may be used more appropriately to meet the changing needs of patients, including the introduction of Patient Group Directions (PGDs), special regulations paving the way for pharmacists to provide medication to clearly specified groups meeting rigid inclusion and exclusion criteria. 7,8

Contraception has been available free of charge through the National Health Service (NHS) since 1974. After the Yuzpe combined oestrogen-progestogen regimen was found to be an effective emergency contraceptive, ${ }^{9}$ the National Association of Family Planning Doctors published guidelines for the use of two combined oral contraceptives for this purpose. ${ }^{10}$ In 1984 a dedicated product (Schering PC4) was licensed as a prescription-only medicine (POM) for EC use $(100 \mu \mathrm{g}$ ethinylestradiol and $1 \mathrm{mg}$ norgestrel taken twice, separated by 12 hours, begun within 72 hours of unprotected intercourse).

The most commonly used source of EC since this time was the general practitioner (GP), but EC could also be obtained from NHS community family planning clinics (FPCs) or young people's sexual health centres [run by the non-governmental organisation (NGO), Brook]. However, access was restricted due to clinic opening times and locations; the embarrassment of revealing the nature of the request for emergency medical attention to the clinic receptionist; and fears regarding disapproval and confidentiality. Hospitals were reluctant to provide what many doctors viewed as a peripheral service. By the mid1990 s, evidence was beginning to emerge suggesting that provision was inadequate: hospital coverage was patchy; there was widespread reluctance to seek EC from GPs, and there was a shortage of clinics open at appropriate times. ${ }^{11-14}$

Between the licensing of PC4 in 1984 and the release of progestogen-only (levonorgestrel) emergency contraceptive (POEC) Levonelle-2 in February 2000, approximately 6 million prescriptions for PC4 were issued. 
In the period 1999-2000, 780000 prescriptions were issued, of which approximately $70 \%$ originated with GPs, with the remainder being issued from NHS FPCs and Brook Advisory Centres. This represents a $420 \%$ increase over the 10-year period from 1989, with the provider mix remaining roughly constant. ${ }^{15}$

By this time, calls for the wider availability of EC had begun to emerge among health professionals. ${ }^{16,17}$ National and international stakeholder meetings on the provision of EC published consensus statements on the need to improve the awareness, uptake and availability of EC, including the reclassification of EC from 'prescription-only medicine' (POM) to 'pharmacy' (P) status in the UK and the formation of the international Consortium for Emergency Contraception. ${ }^{18-20}$ [NB. 'Pharmacy' status is an intermediate status of medications between a general sale license and over-the-counter (OTC) availability, in which the ability of the consumer to purchase the medication is determined by the pharmacist on the basis on client responses to questions (see Box 1).]

\section{Observations}

User behaviour, provider views and policy development A cohort study in Scotland found that providing women with an advance supply of EC reduced the rate of unwanted pregnancies and did no harm. ${ }^{21}$ This finding led to charitable not-for-profit organisations setting up schemes to enable women to purchase an advance supply of EC on private prescription. A study following up EC users' family planning habits showed that the provision of EC did not result in failure to initiate regular contraception or abandonment of it. Instead, the result was that many women used regular contraception for the first time after use of EC.22

Surveys of community pharmacists found general willingness to supply EC if deregulated, although both pharmacists and GPs raised concerns about pharmacists' need for thorough training on all aspects of EC including mode of action, safety, counselling and the ability to refer to local genitourinary medicine clinics if necessary. ${ }^{23-27} \mathrm{As}$ the levonorgestrel findings began to emerge, calls for wider availability of EC intensified among medical professionals. ${ }^{28-30}$

Political attention to EC began to intensify from June 1998, when a series of four debates on pharmacy availability of EC began in Parliament, led by the All-Party Parliamentary Pharmacy Group. At this time, the Minister of Health indicated that there were no plans for EC to be deregulated and the manufacturer of PC4 maintained that it had no intention of applying for a change in licence.

Meanwhile, several deprived areas with high rates of teenage pregnancy were designated as Health Action Zones (HAZs), enabling local health authorities to circumvent the usual legal restrictions and develop innovative pilot schemes locally to widen access to EC. Under these pilot schemes, pharmacists were permitted to supply EC under a PGD (see Context) at no cost. The first pilot scheme began in urban areas of Manchester and Salford (Northwest England) prior to the Christmas and New Year celebrations of 1999-2000, to cover a period when many providers would be closed and demand for EC was anticipated to be high. Fifteen pharmacists enrolled into a training scheme qualifying them to supply EC free of charge to any woman who met the criteria specified in the PGD. By March 2001, the scheme grew to include 120 pharmacists and provided over 12000 clients with EC. ${ }^{31}$ Similar schemes tailored to meet the needs of local populations subsequently began in inner city areas in two additional London districts (Lambeth, Southwark and Lewisham; Kensington, Chelsea and Westminster) and in the Midlands (Walsall and South Derbyshire). These were not, as commonly reported by popular media, government schemes to assess the feasibility of national deregulation, rather they were local initiatives to tackle local problems.

In May 2001, the Department of Health increased the prescribing powers of nurses. ${ }^{32} \mathrm{EC}$ is among the list of POMs that may now be prescribed by specially trained nurse prescribers in various settings.

\section{The advent of POEC}

Levonorgestrel $(750 \mu \mathrm{g})$ was first licensed as a postcoital contraceptive by manufacturer Gedeon-Richter in Hungary in 1980.33 However, it was not until the 1990s that internationally recognised evidence demonstrated levonorgestrel to be a safe and effective EC, with few side effects and contraindications, ${ }^{34,35}$ and a comparative study demonstrated that two doses of $0.75 \mathrm{mg}$ levonorgestrel spaced 12 hours apart was better tolerated and more effective than the Yuzpe regimen. ${ }^{36}$ New research has found that a single dose of $1.5 \mathrm{mg}$ levonorgestrel is equally efficacious, raising the possibility of simpler administration in future. ${ }^{37}$

France was the first country to deregulate POEC (NorLevo marketed by HRA-Pharma) from a prescription drug to an OTC drug, which happened in May 1999, a single day after the new product reached market, leading to confusion amongst the public and health professionals. By 2000, marketing authorisations for POEC had been granted in over 35 countries worldwide, but it remained a POM everywhere except France.

By 1999 the only supplier of EC (PC4) in the UK Schering Health Care Ltd (Schering) had no progestogenonly product available for the UK market. Gedeon-Richter licensed Schering to supply their progestogen-only dedicated EC product as Levonelle-2 (or Postinor-2) in Western Europe (levonorgestrel $750 \mu \mathrm{g}$ ) in October 1999. Levonelle-2 was granted a POM licence by the statutory body responsible for overseeing medicine product regulation in the UK and was launched in February 2000.

\section{The path to deregulation}

Investigation into the feasibility of a change in licence status for Levonelle-2 to a pharmacy licence, allowing pharmacist dispensing without prescription, began immediately. In November 1999, Schering convened a meeting between representatives of all stakeholders, including health professional bodies and NGOs, to agree on a timeframe for the process, including guidelines, training, regulatory issues, consumer communications, political environment and supply. Participants agreed on the need to differentiate the pharmacy product from the prescription product, so Levonelle-2 was to be repackaged more colourfully with an enhanced information booklet, and under the brand Levonelle. Stakeholders agreed that the deregulation process should take a minimum of 12 months, to prevent confusion among health professionals and the public that would result from a rapid change (as in France). A stakeholder working party held regular meetings from February 2000 to manage the transition from POM to $\mathrm{P}$ status.

In January 2000, Schering formally applied to reclassify levonorgestrel-only EC to pharmacy availability, for women aged 16 years and over, within 72 hours of unprotected intercourse. Schering explained this unusual step of introducing an age restriction by citing the lack of clinical trial data on young women and young women's need for an appropriate environment in which they may receive counselling to meet their current and ongoing sexual health needs. Critics however pointed out that there are no age restrictions on the use of levonorgestrel-only EC from a general physician or through PGDs from 
pharmacists in the pilot schemes. The introduction of the age restriction - the age of consent in England and Wales is 16 years - at an early stage in the licensing process may have represented an attempt to minimise the inevitable public and media moral backlash, but was subsequently attacked as representing an unnecessary barrier to access.

After approval of the safety and efficacy evidence, the legal process for deregulation required a public consultation process, with announcements made through the media, on the Internet, and directly mailed to interested parties (including professional bodies, NGOs, religious and advocacy groups). While it is standard practice to consult with professional groups on proposed licensing changes, this usually relates to matters of clinical safety. The process of consultation with the broader community regarding moral implications of licensing change was unique to the EC debate. Responses to the consultation were split equally between those in favour and those against the deregulation. Significant support for the increase in availability and access to EC was received from professional and academic health care bodies, while the responses against the proposal were on 'ethical' grounds, mainly from 'pro-life' groups and morally opposed members of the public.

In July 2000, the Medicines Commission announced that it approved the reclassification and the political process to effect this change was initiated. The reclassification applies pharmacy status to any bioequivalent levonorgestrel-only emergency contraceptive, and not just the named brand Levonelle.

$\mathrm{EC}$ is unique in the level of public interest and media reaction it provoked. Politicians and the manufacturer were criticised for the speed at which the application proceeded; however the normal legal process was followed. Other POMs also recently deregulated to pharmacy status due to a good safety record in comparable processes include cimetidine for hyperacidity and aciclovir for herpes simplex infections. Lessons learnt from the EC experience will affect the proposed future reclassification of other hormonal products, including combined oral contraceptives and hormone replacement therapy. However, speed of access will not be such a crucial issue as it has been for EC.

\section{Role of professional groups}

Professional groups have played a vital role in the lobbying process leading up to the legislative change, and subsequently meeting the necessary training needs among health care professionals in this rapidly changing environment. In anticipation of the forthcoming reclassification, the Royal Pharmaceutical Society of
Great Britain (the regulatory and professional body for pharmacists) set mandatory requirements to be adopted by all pharmacists for the sale of EC as a pharmacy medicine, distributed best practice guidance and established training courses available to all pharmacists to help them to meet the required standards. Guidelines and training materials were distributed to community pharmacists across the country through the professional journal received by all licensed pharmacists. ${ }^{38}$

The Centres for Pharmacy Postgraduate Education (CPPE) (the organisation providing continuing education and professional development opportunities for all community pharmacists in England) compiled and distributed a distance learning course module on EC, and updated its module on long-term contraceptive methods. ${ }^{39,40}$ Accredited training courses and materials to update the knowledge of all health care professionals, including pharmacy assistants and family physicians, have also been prepared by the manufacturer, in addition to national, regional and local pharmacy bodies. ${ }^{41-43}$

\section{Deregulation comes into effect}

The legal amendment allowing pharmacy provision of levonorgestrel-only EC came into effect in January 2001. The manufacturer and professional bodies were able to begin distribution of both the product and the accompanying training materials only after this date. To prevent clients and service providers acting on inaccurate information, the manufacturer and the pharmacy groups set a co-ordinated launch date of 30 January 2001. However, there was enormous public and media confusion about the timings of the changes and opponents continued to lobby for its reversal even after the amendment had come into effect. Challenges were launched and eventually defeated in the House of Commons and House of Lords.

Table 1 shows the current (December 2002) routes of access to emergency hormonal contraception methods.

The cost of obtaining Levonelle from pharmacists was initially fixed at $£ 20$, but increased to $£ 24(€ 37 / \$ 39)$ in September 2002, representing a considerable cost barrier to low-income and unemployed women and students. The continuing pilot schemes have led to a two-tier supply, under which women over 16 years in most areas may purchase Levonelle for a fee, while women of all ages can obtain the same product in slightly different packaging for free if they are within the coverage of a pilot scheme. The existing pilot schemes will continue and be expanded to other areas where the local population cannot afford the high cost of pharmacy purchase. Some local health authorities are developing new PGDs that will run in

Table 1 Routes of access to emergency hormonal contraception methods (current December 2002)

\begin{tabular}{|c|c|c|c|c|}
\hline & \multicolumn{4}{|l|}{ Product (license type) } \\
\hline & Levonelle-2 (POM) & & & Levonelle (P) \\
\hline Who for? & Women of all ages & Women of all ages & $\begin{array}{l}\text { Women of all ages } \\
\text { requesting advance supply }\end{array}$ & $\begin{array}{l}\text { Women aged } 16 \text { years } \\
\text { and over }\end{array}$ \\
\hline $\begin{array}{l}\text { Where? } \\
\text { How? } \\
\text { From whom? }\end{array}$ & $\begin{array}{l}\text { Following consultation } \\
\text { with physicians or nurse } \\
\text { prescribers at GP surgeries, } \\
\text { FPCs, or some young } \\
\text { people's centres }\end{array}$ & $\begin{array}{l}\text { Following PGD consultation } \\
\text { with pharmacists in 'pilot } \\
\text { areas' or at NHS walk-in } \\
\text { clinics }\end{array}$ & $\begin{array}{l}\text { Supplied on an ad hoc basis } \\
\text { following consultation } \\
\text { with GP or available from } \\
\text { FPCs and young people's } \\
\text { centres }\end{array}$ & $\begin{array}{l}\text { From pharmacies following } \\
\text { consultation with pharmacist } \\
\text { (see Box } 1 \text { ) }\end{array}$ \\
\hline Cost? & Free on prescription & Free & $\begin{array}{l}\text { Free on prescription from } \\
\text { some physicians, otherwise } \\
£ 10(£ 15 / \$ 16) \text { from private } \\
\text { providers }\end{array}$ & $£ 24(€ 37 / \$ 39)$ \\
\hline
\end{tabular}

FPC, family planning clinic; GP, general practitioner; NHS, National Health Service; P, pharmacy; PGD, patient group direction; POM, prescription-only medicine. 


\section{Box 1: Client assessment by pharmacis}

'If the client is presenting within 72 hours [of unprotected sex or condom failure] the pharmacist will need to be satisfied whether she:

- Is presenting in person (supplies are not generally appropriate in proxy but may be made in exceptional cases)

- Is aged 16 years or over as this is a requirement of the OTC licence

- Has used any other form of EC within the current cycle

- Is taking any other medication

- Is already pregnant or likely to be pregnant

- Has experienced severe clinical problems (e.g. allergy) with progestogen-containing hormonal contraceptives before

- Had her last period normally

- Had a last period that was not different from usual.'40

parallel to the pharmacy sale of Levonelle enabling public funds to be used to supplement the needs of the most disadvantaged in a less confusing way, by restricting the PGD to segments of the population who are unable to obtain the pharmacy version (e.g. only young or lowincome women).

Box 1 shows the client assessment that the pharmacist is required to carry out in order to decide whether or not to permit the client to purchase EC. If the client falls outside of these criteria, professional guidance recommends that the pharmacist must recommend the client to a local FPC or physician. Pharmacists are therefore required to have a thorough knowledge of local family planning services. Even if EC has been supplied, the pharmacist should advise the client about local services for ongoing care, including contraception and sexual health.

\section{Challenges from the media and 'pro-life' groups}

The deregulation of EC has been viewed by much of the UK media as a moral issue rather than a public health matter. Social issues reporters, rather than health correspondents, wrote most newspaper coverage of this issue. The right-wing press resorted to sensationalist and inaccurate reporting, and investigative journalists set traps designed to catch out pharmacists. Populist newspapers reinforced the stereotype of EC users as feckless teenagers, failing to acknowledge that older women having unprotected sex or experiencing contraception failure currently constitute the majority of users. No acknowledgement has been made that seeking EC may be a responsible and rational act on the part of an individual woman.

Other issues discussed in the media included the suitability of pharmacy premises for a consultation dealing with sensitive information; the need for pharmacists dispensing EC to have access to clients' medical records; and the safety of repeated use. Some criticism was levelled at the narrow focus of the legislative change, and it was argued that if the strategy was to be successful, it should be part of a broad package of sexual health measures, including a programme of public education or advertising campaigns and improvements to sex education in schools. Some of these suggestions were followed up by the NHS in the National Strategy for Sexual Health and $H I V^{44}$ published in July 2001, in which the pilot EC schemes were outlined as a successful case study and a commitment was made to the expansion of other PGDs.

The change in legislation triggered a backlash from 'pro-life' groups. Claims of alarming side effects and encouragement of teenage sex were presented without supporting scientific evidence. In May 2001, the Society for the Protection of the Unborn Child challenged the pharmaceutical supply of Levonelle on the basis that it was an abortifacient illegal under the 1861 Offences Against the Person Act, which prohibits the supply of any 'poison or other noxious thing' with intent to cause miscarriage. The case had massive ramifications, potentially jeopardising the use of all modern fertility control methods including the oral contraceptive pill, intrauterine devices, implants and injections; and the challenge was taken very seriously by the Department of Health, the fpa (formerly the Family Planning Association) and the manufacturer. The case was eventually dismissed by the High Court in April 2002.

\section{Discussion: lessons learned from the UK}

We have presented a case study of events in the UK. Although the characteristics of the populations seeking EC, political processes and drug licensing laws referred to are unique to this context, there remain general lessons learned from this experience that apply equally to other regions lobbying for similar change. Lessons learned from this case study include those detailed below.

\section{Partnership}

Communication between all stakeholders - including the manufacturer, professional groups, NGOs and academic bodies - was essential in developing and acting upon a unified plan of action. Regular stakeholder meetings provided a forum for discussion and collaboration, particularly useful for co-ordinating a consistent message through publicity materials, setting a single unified launch date and defending against the legal challenges from the 'pro-life' group. One pharmaceutical chain that took independent steps to widen access subsequently suspended its facilities for online EC requests following discussions with the Department of Health and the Royal Pharmaceutical Society. Professional groups are working with pharmacies to review the procedures and protocols in place for online prescribing.

Long-term vs short-term priorities

The short-term goal of increasing access to EC for some women was weighed against the long-term goal of increasing access to EC for all women. In this case, the manufacturer's license application specified that pharmacy status was to be made available only to women aged 16 years and over. The introduction of this restriction opened the door to the initiation of legislative change in the first place, and hastened the advent of pharmacy access to EC for women who met the age restriction. Other regions lobbying for change must consider whether making a similar concession would indeed facilitate wider access in the longer term, and ensure alternative routes of access for groups initially excluded.

Transparency and pace

Involving all interested parties in the public consultation kept the deregulation process transparent and gave stakeholders the opportunity to recognise and respond to dissenting views. Criticism on the basis of popular hyperbole and stereotype must be distinguished from practical grounded challenges whose recognition will improve service delivery. Despite accusations of impropriety and undue haste from opponents, it was clear that the normal legal processes had been followed. Changing the legislative framework at a cautious pace reduced public exposure to conflicting messages at a time of change.

Generic license

The pharmacy license was granted to any levonorgestrelonly emergency contraceptive, not to a single named brand. The opportunity therefore remains open for a bio- 
equivalent competitor to enter the market and challenge the market dominance of Levonelle.

\section{Professional groups}

The mobilisation of professional groups is paramount to the success of deregulation. As well as active involvement in all the stakeholder group meetings and processes facilitating change, the professional body representing pharmacists used its network of all pharmacists to keep members informed and reach blanket coverage regarding training requirements and opportunities.

\section{Multiple routes vs duplication of efforts}

Training materials to meet the new needs of community pharmacists were made widely available and accredited for professional development through different bodies (local/national, manufacturer/professional groups). Alternative materials were available geared to the needs of different groups (e.g. medicines counter assistants). The value of a multiplicity of routes to access the information must be evaluated against the efficiency of groups duplicating each other's efforts.

\section{Public awareness}

Confusion remains in the public perception of EC. A survey showed that over $40 \%$ of women in the UK still do not know that EC can be taken up to 72 hours after unprotected sex, and other erroneous beliefs about its side effects and mode of action persist. ${ }^{1}$ Advertising prescription products directly to consumers is unlawful in the UK, so the shift to pharmacy status represented an unprecedented opportunity for the manufacturer to place the first advertisements for a hormonal contraceptive. However, it was not until December 2001 almost a year after the legislative change - that the manufacturer launched a campaign to advertise Levonelle through magazines and radio stations, educating women about their new contraceptive option. Opportunities exist to address public knowledge and opinion using multiple channels for additional publicity, but debate remains as to whose responsibility it is to re-educate the public.

\section{Conclusion: access improved but barriers remain}

It is clear that further work is needed regarding what is required from health professionals to support and encourage 'good sexual health behaviour'. Even among health professionals, dissent remains regarding whether the use of EC falls outside a model of 'responsible sexual behaviour' in which every sexual encounter is planned and negotiated with both partners fully prepared. The reality is that for many women the use of EC is a responsible rational decision under their circumstances, e.g. as a second line of defence following condom failure. In any case, health care personnel should avoid implied moral judgements of irresponsibility, which will deter rather than educate their clients. While pharmacist provision may reduce the opportunity for women to talk with their physician about their sexual health, it may also increase women's opportunity for any contact time at all with a health care professional before pregnancy.

There is still a long way to go before EC is available to all who need it at the time when they need it. The recent changes in the UK must be seen as a vital part of a continuing process to improve access to EC, whilst acknowledging that numerous barriers to access remain:

Client age was an understandable area of initial caution in the initial legislative change. A new licence application would be required in order to remove the restriction on under-16s, which might become an easier process once the initial political controversy has subsided and the new route of EC provision becomes more accepted.
Ability to pay is a major determinant of demand for EC. The high price of obtaining EC from a pharmacist acts as a deterrent to low-income women, including students and unemployed women. Perhaps only by running parallel PGD schemes can this barrier be overcome. A recent survey found that women aged 18-29 years preferred the new route of access to EC through pharmacists, but that the charge of $£ 20\left({ }^{€} 30 / \$ 33\right)$ was thought to represent a prohibitive barrier to access. ${ }^{45}$ Since that survey, price has subsequently increased even further to $£ 24$ ( $€ 37 / \$ 38$ ).

Before any women over 16 years can purchase EC from a pharmacist she must still answer several detailed questions about her sexual activity and menstrual cycle. Some women will undoubtedly consider this to be an unwelcome intrusion discouraging them from seeking EC. It has been suggested that the pharmacist should simply ensure that the woman is aware that $\mathrm{EC}$ will not prevent a pre-existing pregnancy and to provide her with information on her risk of contracting a sexually transmitted infection.

Despite a growing body of evidence in support of advance provision of $\mathrm{EC}$, access by this route remains limited, perhaps due to a lack of public education and judgmental attitudes expressed through the media. Other routes of access for future exploration include the ability to obtain EC over the Internet and phone, as with other pharmacy products.

The remaining barriers to access combine to create a climate where EC is still perceived to be a difficult product to distribute and use, both in terms of its clinical effects and moral implications, requiring special management to prevent the dangers of 'abuse'. A clear need has emerged to remove the stigma associated with EC and present it as part of a range of responsible contraceptive options. The evolving market and policy environment will continue to challenge the remaining barriers to access. It is to be hoped that the lessons learnt from the pioneering changes in the UK will be instructive for other regions lobbying for deregulation of EC.

\section{Acknowledgements}

The author wishes to thank Toni Belfield (fpa), Francine Coeytaux, Ann Furedi (HFEA), Anna Glasier (Lothian Primary Care NHS Trust), Peter Hall (Reproductive Health Alliance) and Chris Miller (Schering Health Care Ltd) for valuable comments on an earlier draft of this article.

\section{Statements on funding and competing interests}

Funding. This research was commissioned and funded by the Californian Pharmacy Access Partnership Project and Reproductive Health Alliance (RHA).

Competing interests. The majority of this paper was written while the author was employed by RHA, which has closed. During this employment the author also wrote the RHA report Emergency contraception - the UK experience published by RHA, London, 2001. This report served as a background document for this article.

References

1 Dawe F, Meltzer H. Contraception and sexual health 2000. London: Office for National Statistics, 2002.

2 Duncan G, Harper C, Ashwell E, et al. Termination of pregnancy: lessons for prevention. Br J Fam Plann 1990; 15: 112-117.

3 Griffiths M. Contraceptive practices and contraceptive failures among women requesting termination of pregnancy. Br J Fam Plann 1990; 16: 16-18.

4 Bromham DR, Cartmill RS. Knowledge and use of secondary contraception among patients requesting termination of pregnancy. BMJ 1993; 306(6877): 556-557.

5 Trussell J. Contraceptive efficacy. In: Hatcher R (ed.), Contraceptive technology. New York, NY: Ardent Media, 1998.

6 Teenage pregnancy - social exclusion unit. London: The Stationery Office, 1999.

7 Review of prescribing, supply and administration of medicines (Crown Report). London: Department of Health, 1999.

8 Pharmacy in the future - implementing the NHS plan. London: National Health Service, Department of Health, 2000.

9 Yuzpe A, Lancee W. Ethinylestradiol and dl-norgestrel as a postcoital contraceptive. Fertil Steril 1977; 28: 932-936.

10 Clinical and Scientific Advisory Committee. Postcoital contraception 
- notes for doctors. Br J Fam Plann 1983; 9: 42-44.

11 Crosier A. women's knowledge and awareness of emergency contraception. Br J Fam Plann 1996; 22: 87-90.

12 Gbolade BA, Elstein M, Yates D. UK accident and emergency departments and emergency contraception: what do they think and do? J Accid Emerg Med 1999; 16: 35-38.

13 Hadley A. Picking up the pieces. Pract Nurse 15 September 1995: 169-173.

14 Peckham S. Preventing teenage pregnancy: developing effective services for young people. Health Educ 1997; 3: 103-109.

15 Contraceptive services, England 1999-2000 statistical bulletin. London: National Health Service, 2000.

16 Glasier A. Emergency contraception: time for de-regulation? $\mathrm{Br} J$ Obstet Gynaecol 1993; 100: 611-612.

17 Drife JO. Deregulating emergency contraception. BMJ 1993; 307 695-696.

18 Royal College of Obstetricians and Gynaecologists/Faculty of Family Planning and Reproductive Healthcare Joint Statement on Emergency Hormonal Contraception, 1995.

19 Paintin D (ed.). The provision of emergency hormonal contraception. London: Royal College of Obstetricians and Gynaecologists Press, 1995.

20 Consensus statement on emergency contraception. Contraception 1995; 52: 211-213.

21 Glasier A, Baird D. The effects of self-administering emergency contraception. N Engl J Med 1998; 339: 1-4.

22 Rowlands S, Devalia H, Lawrenson R, et al. Repeated use of hormonal emergency contraception by younger women in the UK. $\mathrm{Br}$ J Fam Plann 2000; 26: 138-143.

23 Barrett G, Harper R. Health professionals' attitudes to the deregulation of emergency contraception (or the problem of female sexuality). Sociol Health Illn 2000; 22: 197-216.

24 Blackwell D. Pharmacists' concerns and perceived benefits from the deregulation of hormonal emergency contraception (HEC). Br J Fam Plann 1999; 25: 100-104.

25 Ziebland S, Graham A, McPherson A, et al. Concerns and cautions about prescribing and deregulating emergency contraception: a qualitative study of general practitioners using telephone interviews. Fam Pract 1998; 15: 449-456.

26 Seston EM, Holden K, Cantrill J. Emergency hormonal contraception: the community pharmacy perspective. J Fam Plann Reprod Health Care 2001; 27: 203-208.

27 Ralph SG, Preston A, Clarke J. Over-the-counter advice for genital problems: the role of the community pharmacist. Int J STD AIDS 2001; 12: 513-515.

28 Webb A. Emergency contraception: is it time to change method? BMJ 1999; 318(7180): 342-343.
29 Guillebaud J. Time for emergency contraception with levonorgestrel alone Lancet 1998; 352(9126): 416-417.

30 Cayley J. Emergency contraception. BMJ 1995; 311(7008): 762-763.

31 O'Brien K, Gray N. Supplying emergency hormonal contraception in Manchester under a group prescribing protocol. Pharm J 2000; 264(7090): 518-519.

32 Department of Health. Extending independent nurse prescribing within the NHS in England: a guide for implementation. London: Department of Health, 2002

33 Farkas M, Apró G, Sas M. Clinico-pharmacological examination of Postinor (750 $\mu \mathrm{g}$ d-norgestrel). Ther Hung 1981; 29: 22-30.

34 Ho P, Kwan M. A prospective randomized comparison of levonorgestrel with the Yuzpe regimen in post-coital contraception. Hum Reprod 1993; 9: 389-392.

35 Glasier A. Emergency postcoital contraception. N Engl J Med 1997; 337(15): 1058-1064.

36 Randomised controlled trial of levonorgestrel versus the Yuzpe regimen of combined oral contraceptives for emergency contraception. Task Force on Postovulatory Methods of Fertility Regulation. Lancet 1998; 352(9126): 428-433.

37 Hertzen HV, Piaggio G, Ding J, et al. Low dose mifepristone and two regimens of levonorgestrel for emergency contraception: a WHO multicentre randomised trial. Lancet 2002; 360(9348): 1803.

38 Royal Pharmaceutical Society of Great Britain. Practice guidance on the supply of emergency hormonal contraception as a pharmacy medicine. Pharm J 2000; 265: 890-892.

39 Centres for Pharmacy Postgraduate Education. Contraception: a distance learning course for pharmacists. London: Her Majesty's Stationery Office, 2000.

40 Centres for Pharmacy Postgraduate Education. Emergency hormonal contraception. London: Her Majesty's Stationery Office, 2000.

41 Emergency hormonal contraception - training pack for medicines counter assistants. London: National Pharmaceutical Association, 2001.

42 Schering Primary Care Education Programme Regular and emergency contraception - long term methods of contraception module. Burgess Hill: Schering, 2001

43 Schering Primary Care Education Programme. Regular and emergency contraception - emergency hormonal contraception module. Burgess Hill: Schering, 2001

44 Department of Health. Better prevention, better services, better sexual health: the National Strategy for Sexual Health and HIV. London: Department of Health, 2001

45 Folkes L, Graham A, Weiss M. A qualitative study of the views of women aged 18-29 on over-the-counter availability of hormonal emergency contraception. J Fam Plann Reprod Health Care 2001; 27: 189-192.

\title{
A 6-month pilot of a collaborative clinic between genitourinary medicine services and a young persons' sexual health clinic
}

\author{
Deborah Beddard, RGN, SCM, Brook in Manchester; Swatantrata Chandiok, MD, FRCOG, Department of Genitourinary \\ Medicine, South Manchester University Hospital Trust; Philippa James, MRCGP, DFFP, Brook in Manchester; Antonia \\ Russell, RGN, BA, Department of Genitourinary Medicine, South Manchester University Hospital Trust, Manchester, UK
}

Correspondence: Dr P James, Boundary Medical Practice, 63 Booth Street West, Hulme, Manchester M15 6PR, UK

(Accepted 12th September 2002)

Journal of Family Planning and Reproductive Health Care 2003; 29(2): 40-42

\begin{abstract}
Objective. To investigate whether situating a genitourinary medicine (GUM) clinic within a Brook centre is successful in attracting a younger client group than that traditionally seen in GUM clinics within hospitals.

Design. A descriptive study of a 6-month pilot clinic.

Setting. Brook in Manchester. A community clinic providing sexual health advice to clients under the age of 25 years. With the collaboration of Withington Hospital GUM Department, Manchester.

Participants. All clients under the age of 25 years attending the pilot GUM clinic.

Main outcome measures. The age of the clients attending and the diagnosis made.

Results. A total of 137 visits were made by 93 clients. Under-16s comprised $6 \%$ of all visits compared to $1.5 \%$ at
\end{abstract}

